\title{
A New Iterative Procedure for Deconvolution of Seismic Ground Motion in Dam-Reservoir-Foundation Systems
}

\author{
Gurinderbir S. Sooch ${ }^{1,2}$ and Ashutosh Bagchi ${ }^{1}$ \\ ${ }^{1}$ Department of Building, Civil and Environmental Engineering, Concordia University, Montreal, QC, Canada H3G $1 M 8$ \\ ${ }^{2}$ Hatch Ltd., Niagara Falls, ON, Canada L2E 7J7 \\ Correspondence should be addressed to Ashutosh Bagchi; ashutosh.bagchi@concordia.ca
}

Received 28 May 2014; Accepted 14 August 2014; Published 18 September 2014

Academic Editor: Giuseppe Marino

Copyright (c) 2014 G. S. Sooch and A. Bagchi. This is an open access article distributed under the Creative Commons Attribution License, which permits unrestricted use, distribution, and reproduction in any medium, provided the original work is properly cited.

\begin{abstract}
The concrete gravity dams are designed to perform satisfactorily during an earthquake since the consequence of failure is catastrophic to the downstream communities. The foundation in a dam is usually modeled by a substructuring approach for the purpose of seismic response analysis. However, the substructuring cannot be used for solving nonlinear dynamic problems that may be encountered in dam-reservoir-foundation systems. For that reason, the time domain approach is preferred for such systems. The deconvolved earthquake input model is preferred as it can remove the seismic scattering effects due to artificial boundaries of the semi-infinite foundation domain. Deconvolution is a mathematical process that allows the adjustment of the amplitude and frequency contents of a seismic ground motion applied at the base of the foundation in order to get the desired output at the dam-foundation interface. It is observed that the existing procedures of deconvolution are not effective for all types of earthquake records. A modified procedure has been proposed here for efficient deconvolution of all types of earthquake records including high-frequency and low-frequency ground motions.
\end{abstract}

\section{Introduction}

The number and size of hydroelectric dams increased significantly across Canada since 1910 [1]. Although concrete gravity dams have been observed to perform well during an earthquake, there are some incidents of such dams shaken by strong earthquakes [2]. For example, Shih-Kang Dam in Taiwan suffered complete loss of the reservoir during Chi-Chi earthquake in September 1999 [3]. Hsifengkiang dam in China and Koyna dam in India also sustained significant damage in 1962 and 1967 earthquakes, respectively $[4,5]$. Therefore, monitoring and assessment of dam performance are very important for ensuring dam safety $[6,7]$. To study the seismic performance of a concrete gravity dam numerically, it is necessary to model the system realistically by incorporating the effects of interaction among dam, foundation, and reservoir. Chakrabarti and Chopra [8] and Fenves and Chopra [9] studied the dam-foundation interaction effect in the frequency domain using viscoelastic half-space solutions to model the foundation. In many cases, the analytical models based on frequency domain analysis are insufficient as they cannot be used to model nonlinear and nonhomogenous geometrical and material properties of the dam or foundation. In such cases, analysis must be done in time domain.

Clough et al. [10] and Léger and Boughoufalah [11] studied a set of various models to simulate different earthquake input mechanisms. In some cases, deconvolution of input earthquake motion [12] was necessary. Deconvolution is a mathematical process which allows the adjustment of the amplitude and frequency content of an earthquake ground motion to achieve the desired output motion observed by the structure. The deconvolution is a signal processing technique where one signal is usually obtained from another by pointby-point division of the two signals in the Fourier domain, by dividing the Fourier transforms of the two signals and then inverse-transforming the result. Practically, Fourier deconvolution in signal processing is an artificial way to 
reverse the result of a convolution occurring in the physical domain, for example, to reverse the signal distortion effect of an electrical filter or of the seismic wave propagating through an elastic medium. Since the signal distortion is specific to the physical medium through which the signal passes, the deconvolution procedure to obtain the input signal from the output or the distorted signal is domain specific.

Computer program SHAKE developed by Schnabel et al. [13] for deconvolution of seismic ground motion was used in many previous studies [11, 14, 15]. However, the deconvolution process using the procedure used in SHAKE is quite cumbersome as the response obtained through such analysis is very sensitive to the values of the controlling parameters such as the shear modulus and the equivalent viscous damping ratio in case of flexible foundations [11]. The objective of this paper is to develop a new procedure for the deconvolution of ground motions, which is applicable for all types of ground motions. Luk et al. [14] and Polam et al. [15] recommended different constraint models to represent foundation models. In the present study, a similar approach is undertaken and implemented using a commercial software ABAQUS [16].

\section{Seismic Wave Scattering in Dam-Foundation System}

To evaluate the response of a dam during a seismic event, the ground motion acceleration is applied at the base of the foundation, which propagates vertically through elastic wave propagation mechanism until it reaches the top of the foundation. The size of the foundation in a numerical model is finite compared to the semi-infinite foundation in the physical model. Hence, the seismic waves reflect from the artificial boundaries due to the finite size of the numerical model, which may alter the frequency contents and amplitudes of a ground motion time history signal as the wave propagates through the deformable foundation rock. To account for such wave scattering effect, it is recommended to use transmitting boundaries or deconvolved ground motion records [17].

\section{Deconvolution of Seismic Ground Motion}

In this method, first, a deconvolution analysis is performed to determine the acceleration time history that can be applied to the base of the foundation to reproduce the specified free-field acceleration time history at the base of a dam (Figure 1). The calibrated base acceleration history is then applied to the base of the foundation to perform the seismic analysis. Deconvolution analysis can be performed using a mathematical process as described in [12], which is explained below. Deconvolution analysis allows the adjustment of the amplitude and frequency contents of an earthquake ground motion applied at the base of the foundation to achieve the desired output ground acceleration at the dam-foundation interface. Initially, the ground acceleration applied at the

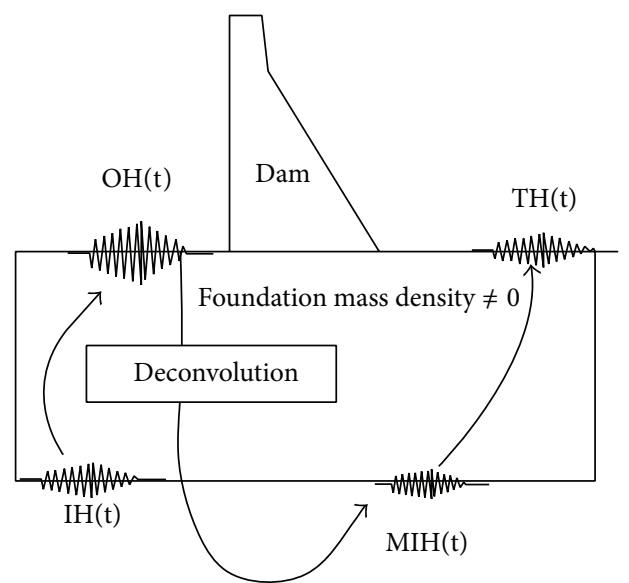

FIGURE 1: Representation of deconvolution procedure.

base of the foundation is assumed to be the same as the free-field ground acceleration. The acceleration time history at the top surface (i.e., dam-foundation interface) is then estimated by solving the wave propagation problem of the dam-foundation system using the finite element analysis technique. This estimated or reproduced ground acceleration at a reference point on the dam-foundation interface is then compared to the original free-field ground acceleration after transforming both signals into the frequency domain using Fourier analysis. Fast Fourier transform (FFT) and Inverse Fast Fourier transform (IFFT) algorithms developed by [18] allow the transformation of time domain signal into a frequency domain signal or visa-versa, respectively. FFT of a time series yields complex Fourier amplitude values for a set of discrete frequencies. The complex Fourier amplitudes are then converted into absolute values to obtain the Fourier amplitude spectrum. On the other hand, IFFT of a set of complex Fourier amplitudes for a set of discrete frequencies yields a time domain signal.

As mentioned earlier, the free-field acceleration or any arbitrary signal is initially applied at the base of the foundation, and, by solving the wave propagation problem, the acceleration signal at a selected point at the top of the foundation is obtained. The synthesized and free-field acceleration signals at the top of the foundation are then compared in the frequency domain, and a correction factor for each frequency is computed using the ratio of the Fourier amplitudes of the synthesized and free-field ground acceleration signals in a given iteration. The acceleration signal applied at the base of the foundation is modified using the correction factor for each frequency. The modified acceleration history is then transformed back into time domain acceleration signal by employing IFFT, and the analysis of the wave propagation analysis for the foundation system is repeated with the modified ground acceleration applied at the base of the foundation. The procedure is iterated until the original freefield ground motion at the top of the foundation closely 
matches the reproduced ground motion record generated by using the modified ground motion applied at the base of the foundation. The resulting ground motion at the foundation-base would be called the deconvolved ground motion that should be used in the dynamic analysis of the dam-foundation system.

\section{Modified Deconvolution Procedure}

The existing iterative procedure for deconvolution as discussed in the previous section does not produce appropriate results for high-frequency ground motion records as will be shown later. However, it works quite well for the low-frequency ground motion records in some cases. To overcome such limitation, a modified procedure has been proposed in this section. Figure 2 shows a flowchart for the modified deconvolution procedure. Similar to the existing procedure, here, the reproduced acceleration history at the top of the foundation is compared to the free-field acceleration, both converted to frequency domain using Fourier analysis. However, the correction factors to adjust the deconvolved signal are determined differently. Instead of adjusting the Fourier amplitudes at different frequencies, the response spectral ordinates at different frequencies are adjusted. The response spectra of the reproduced acceleration time history and the input ground motion (i.e., original free-field acceleration) are computed for the discrete set of frequencies. The correction factors are calculated for each frequency by the ratio of the target response spectrum amplitude $\mathrm{TSa}(j)$ to the response spectrum amplitude $\mathrm{RSa}(j)$ of the reproduced acceleration history:

$$
\mathrm{CF}(j)=\frac{\mathrm{TSa}(j)}{\mathrm{RSa}(j)} .
$$

This correction factor is then applied to the frequency domain acceleration signal applied at the base of the foundation. The complex Fourier coefficients (real part $a(j)$ and the imaginary part $b(j))$ of the acceleration at the foundation-base are modified using (2). The modified acceleration signal is then transformed back to time domain using IFFT. The analysis of the dam-foundation system is carried out with the modified time history of ground acceleration applied at the base of the foundation. The procedure is iterated until the reproduced ground motion at the base of the dam closely matches the original free-field ground motion. The response spectrum of the reproduced ground motion at the top of the foundation should match the target spectrum.

The response spectrum produces the plots of the maximum response acceleration for all possible linear single degree of freedom systems to a given ground motion for a given level of damping (assumed 5\% in this analysis). The correction factors calculated through an iterative process with the existing deconvolution procedure (Section 3) contain errors due the approximate nature of FFT and IFFT. Therefore, the error is compounded as the iterations advance. The modified procedure compares the output response with the target response spectrum rather than the absolute values
TABLE 1: Material properties.

\begin{tabular}{lcc}
\hline Material & Concrete & Rock \\
Elastic modulus (MPa) & $3.45 \times 10^{4}$ & $2.76 \times 10^{4}$ \\
Poisson's ratio & 0.2 & 0.33 \\
Unit weight $\left(\mathrm{kN} / \mathrm{m}^{3}\right)$ & 23.5 & 25.9 \\
\hline
\end{tabular}

of the Fourier amplitudes, which are an approximate representation of the complex-valued Fourier spectrum. Large civil infrastructure such as a dam is usually designed or evaluated using a given response spectrum specified in the relevant code of practice. The modified deconvolution procedure ensures that the errors introduced during the FFT and IFFT are minimized, as the correction factors are calculated for each frequency by the ratio of the target response spectrum amplitude $\mathrm{TSa}(j)$ to the response spectrum amplitude $\mathrm{RSa}(j)$ of the reproduced acceleration history. This modified deconvolution procedure is very effective compared to the existing deconvolution procedure. A case study is presented in Section 7 to demonstrate the effectiveness of the modified deconvolution procedure.

To determine the closeness of the response spectrum of reproduced ground motion to the free-field ground motion, the coefficient of determination $\left(R^{2}\right)$, as defined in the texts in statistics, has been utilized. A value of 1 for $R^{2}$ represents a perfect match of the two data series which are represented here by the spectra of the original and the reproduced ground accelerations. The proposed modified deconvolution procedure is found to work very well for both high- and lowfrequency ground motions:

$$
\begin{aligned}
& a(j)_{\text {modified }}=a(j) * \mathrm{CF}(j) \\
& b(j)_{\text {modified }}=b(j) * \mathrm{CF}(j) .
\end{aligned}
$$

\section{Finite Element Model and Constraints}

Two geometrically different monoliths of concrete gravity dams have been considered here to study the seismic wave scattering in dam-foundation systems. Figure 3 shows the two geometric configurations, G-1 and G-2, which are considered here. G-1 represents a geometrical configuration which is commonly used for dams. However, G-2 has an irregular foundation. These kinds of irregular foundations are popular in large surface toe hydroelectric projects located on good-quality foundation rock $[19,20]$. The assumed material properties are summarized in Table 1. Five percent material damping is considered in the analysis with Rayleigh damping assumptions. The hydrodynamic interaction is modeled by added mass model considering incompressible water. The dam and foundation are modeled using four-noded bilinear plain-strain finite elements. To perform the deconvolution procedure, the soil must act as a one-dimensional soil column. To simulate the one-dimensional soil column behavior, a set of constraints needs to be applied on the boundaries. Figure 4 shows the representation of constraints which allow the shear deformations in foundation to simulate the propagation of waves but they do not allow the foundation 

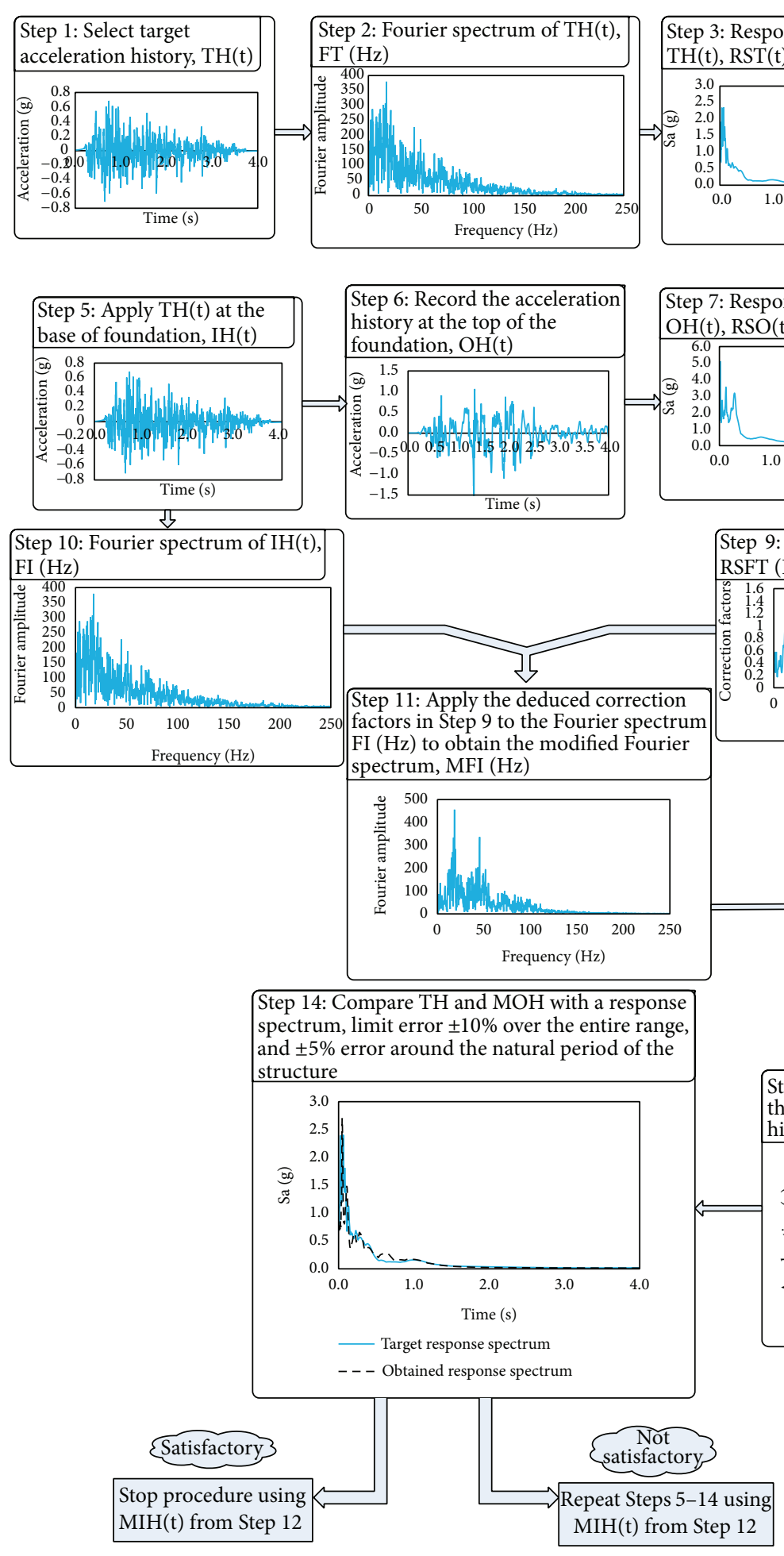

FIgURE 2: Proposed deconvolution procedure.

Step 11: Apply the deduced correction factors in Step 9 to the Fourier spectrum FI $(\mathrm{Hz})$ to obtain the modified Fourier spectrum, MFI $(\mathrm{Hz})$

Step 14: Compare TH and $\mathrm{MOH}$ with a response (n)
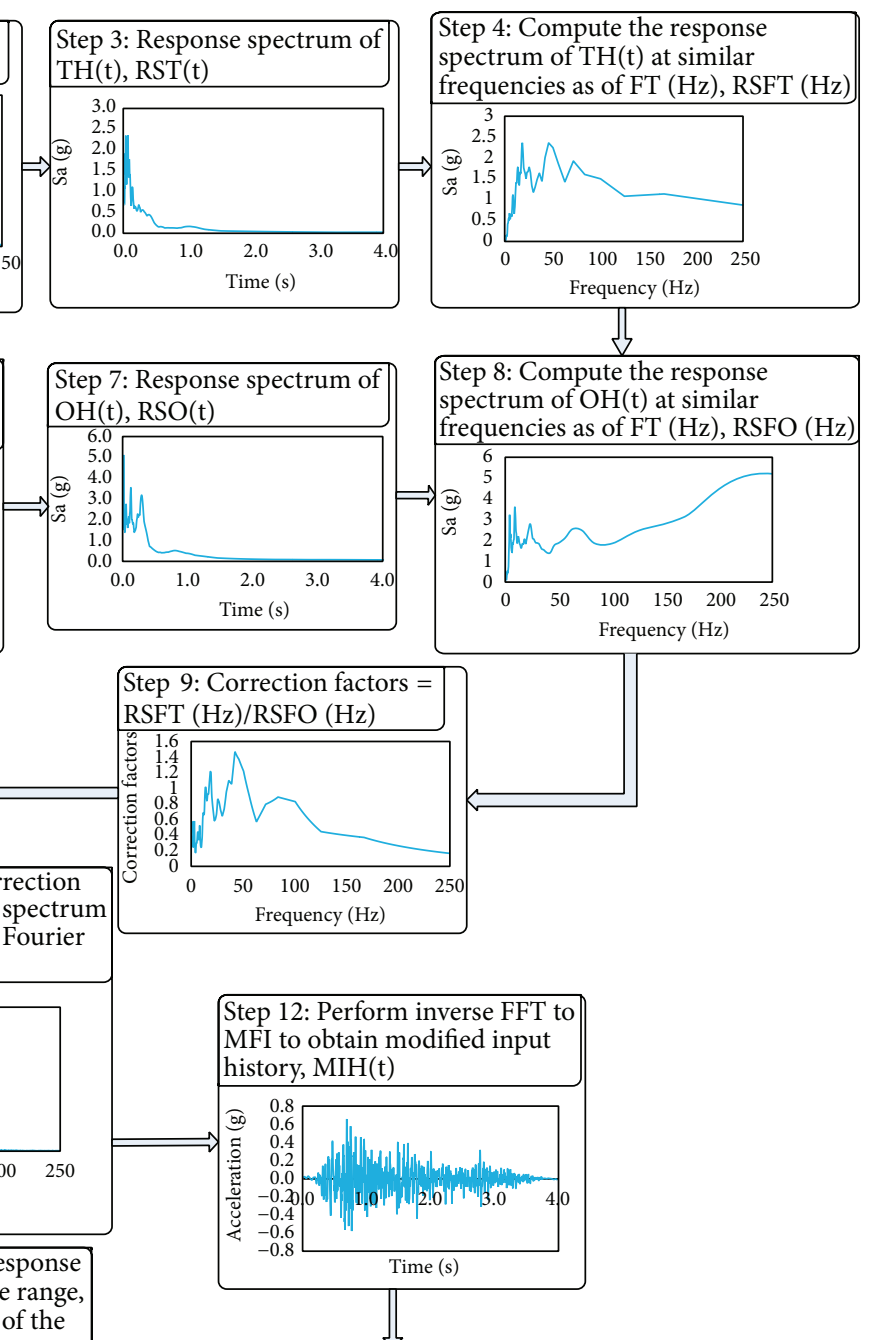

Step 13: Apply the MIH(t) at the base of the foundation and record acceleration history at the top of the foundation, $\mathrm{MOH}(\mathrm{t})$

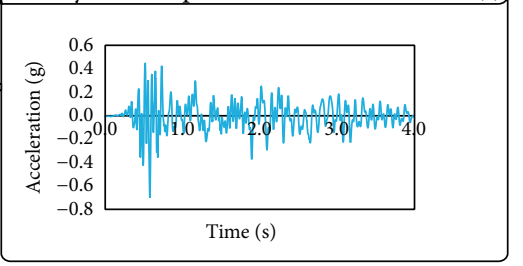



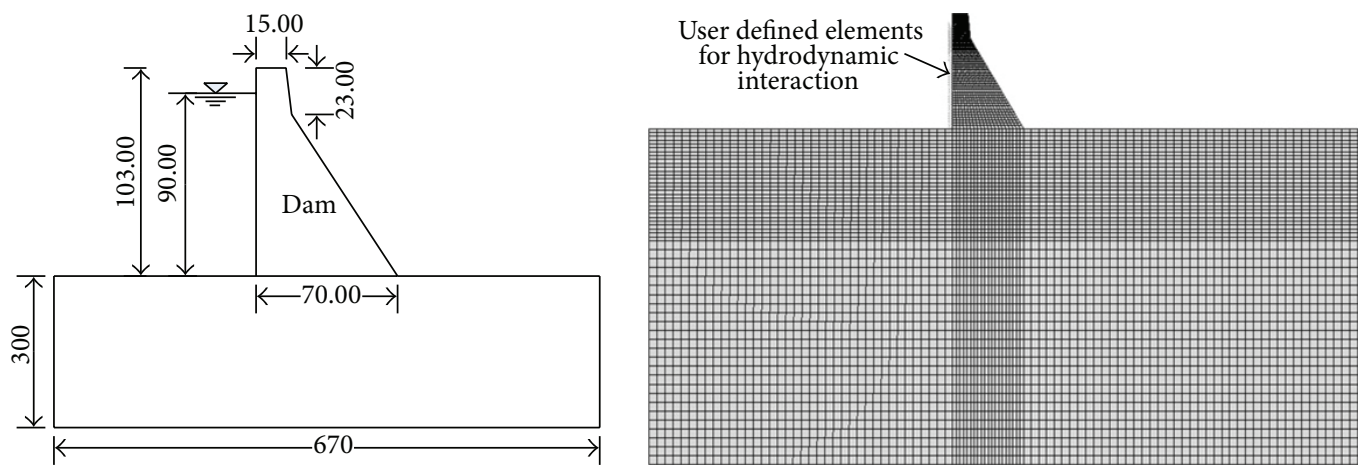

(a)
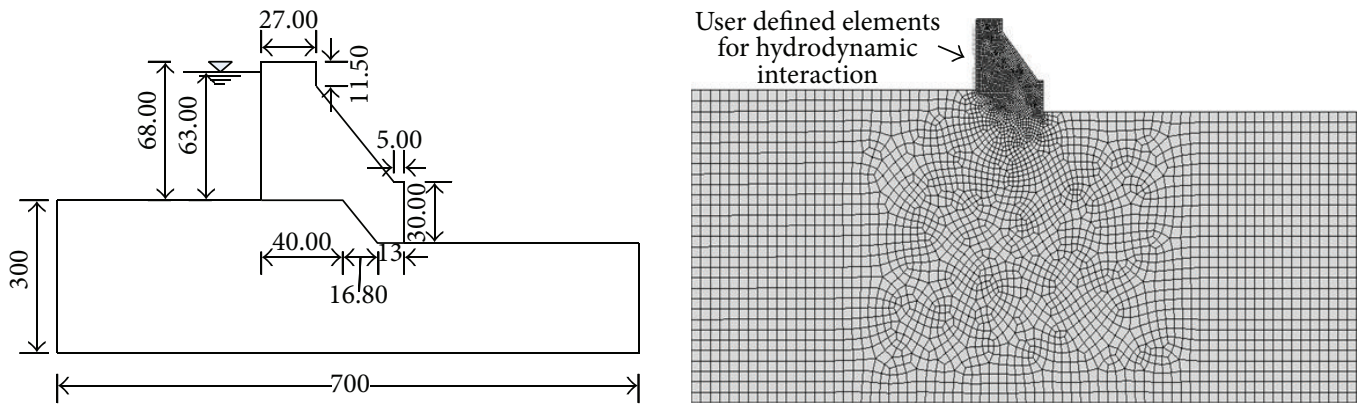

(b)

FIGURE 3: Dam-foundation system: (a) Geometry G-1 and (b) Geometry G-2.

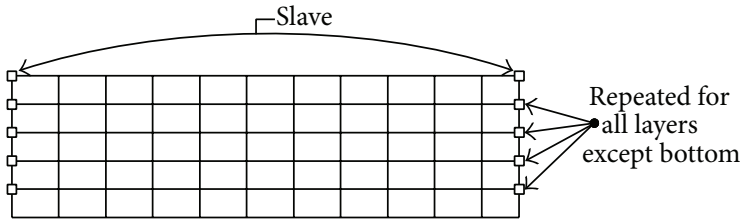

(a)

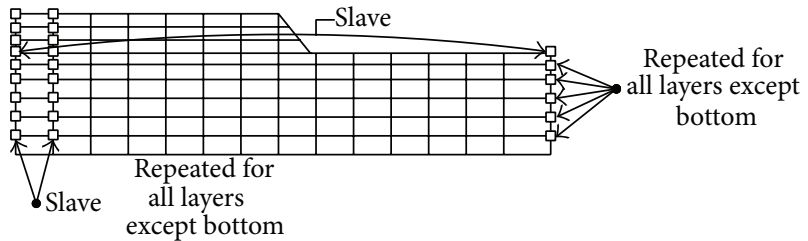

(b)

FIGURE 4: Representation of constraints.

to deform in bending mode. Foundation size should be sufficiently large to accommodate the local displacements near the dam. Based on the study by Bayraktar et al. [21], the size of the foundation is assumed to be three times the height of the dam or $3 \mathrm{H}$, which is almost equal to $300 \mathrm{~m}$ on each side of the dam in this case.

\section{Selection of Seismic Ground Motions}

Two different suites of ground motion records containing high-frequency and low-frequency contents have been considered here. They contain both simulated and actual ground motion records. The simulated records have been chosen based on those developed in Tremblay et al. [22], while the ground records of past earthquakes have been obtained from the PEER database at the University of California, Berkeley [23]. The first suite of high-frequency ground motion includes the following records: (i) simulated record for Eastern Canada having a magnitude of M6 and a distance of $30 \mathrm{~km}$, (ii) simulated record for Eastern Canada having a magnitude of $\mathrm{M} 7$ and a distance of $70 \mathrm{~km}$, and (iii) San Fernando 1971 earthquake record. These ground motion records are referred to here as $\mathrm{M}$ number $1, \mathrm{M}$ number 2, and $\mathrm{M}$ number 3, respectively. The horizontal and vertical components of the ground motions are denoted here by $\mathrm{H}$ and $\mathrm{V}$, respectively (Figures $5(\mathrm{a})$ and $5(\mathrm{~b})$ ). The second suite of low-frequency ground motions includes the following records: (i) Friuli 1976 earthquake record, (ii) Livermore 1980 earthquake record, and (iii) simulated record for Western Canada having a magnitude of M6.5 and a distance of $30 \mathrm{~km}$. These ground motion records are referred to here as $\mathrm{V}$ number $1, \mathrm{~V}$ number 2 , and $\mathrm{V}$ number 3, respectively (Figures 5(c) and 5(d)). The horizontal components of the high-frequency ground motions have been scaled according to an expected level of seismic hazard (with $2 \%$ probability of exceedance in 50 years) that corresponds to Montreal (Eastern Canada). On the other hand, the horizontal components of the low-frequency ground motions 


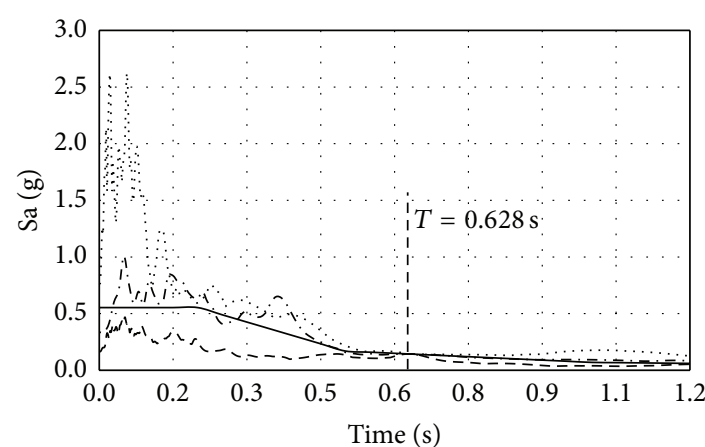

$\begin{array}{lll}\text { - Target Montreal }(\mathrm{H}) \quad \cdots \cdots & \mathrm{M} \# 2(\mathrm{H}) \\ ---\mathrm{M} \# 1(\mathrm{H}) & \cdots & \mathrm{M} \# 3(\mathrm{H})\end{array}$

(a)

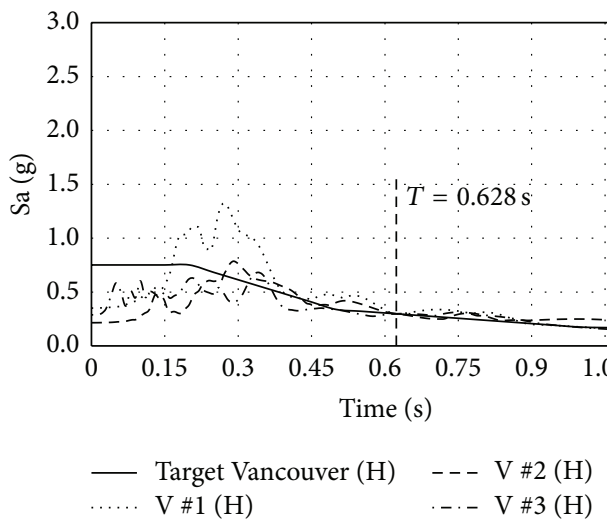

(c)

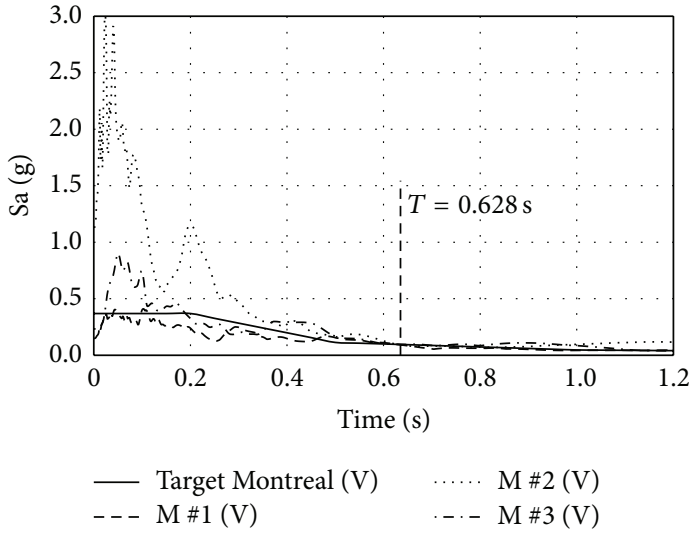

(b)

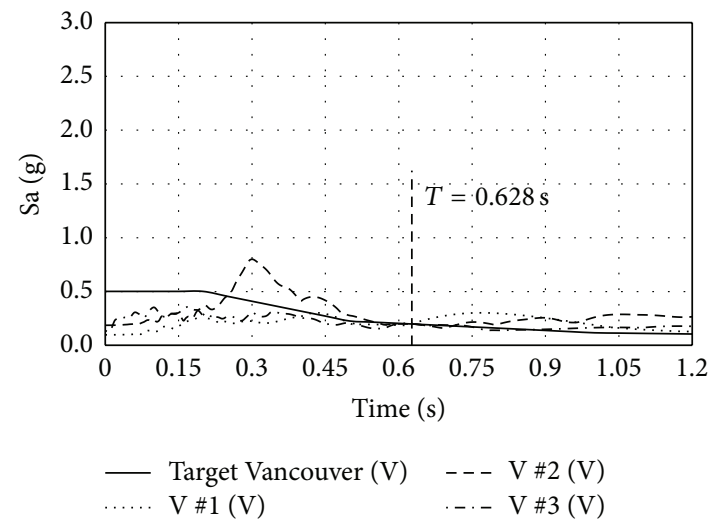

(d)

FIGURE 5: Response spectra for the ground motion records: (a) Montreal-horizontal components, (b) Montreal-vertical components, (c) Vancouver-horizontal components, and (d) Vancouver-vertical components.

have been scaled according to an expected level of seismic hazard that corresponds to Vancouver (Western Canada). The vertical components of all ground motions have been scaled to two-thirds of the respective horizontal components. Figure 5 shows the scaled response spectra of the ground motions. The time periods of the dam-foundation systems for Geometries G-1 and G-2 are found to be 0.628 s and 0.67 s, respectively.

\section{Performance of the Modified Deconvolution Procedure}

Figures 6,7 , and 8 present the results of the different deconvolved ground acceleration time history by modified (MDP) and existing deconvolution procedures (EDP) for dam-foundation system, G-1. It is observed from the results that the MDP works very well for both high-frequency and low-frequency ground motions. However, EDP produces acceptable results only in the cases of some low-frequency ground motions, such as $\mathrm{V}$ number 1 and $\mathrm{V}$ number 2, but does not work in other cases, such as $\mathrm{V}$ number 3. To demonstrate the effectiveness of MDP compared to EDP, the results of deconvolution have been discussed for the following earthquake records: $M$ number 3 representing a high-frequency record and $\mathrm{V}$ number 2 and $\mathrm{V}$ number 3 representing low-frequency records.

Figure 6 shows the response spectra of the original record along with those generated from the deconvolved records. As indicated by Figures 6(a) and 6(b), for M number 3, the MDP spectra match very closely with the spectra of the free-field (original) ground motion for both horizontal and vertical components, while the EDP spectra do not match very well. Figures 6(c) and 6(d) show the comparison of the original spectra for $\mathrm{V}$ number 2 with the MDP and EDP spectra for the horizontal and vertical components. In this case, both MDP and EDP spectra are observed to be close to the spectra of the original ground motion. Figures 6(e) and 6(f) show the comparison of the original spectra for $\mathrm{V}$ number 3 with the MDP and EDP spectra for the horizontal and vertical components. In this case, MDP spectra match very closely with the spectra of the free-field (original) ground motion, while the EDP spectra do not match very well. This is similar to what has been observed in the case of $\mathrm{M}$ number 3 record.

Figure 7 shows the values of the coefficient of determination $\left(R^{2}\right)$ for different iterations for MDP and EDP in the 


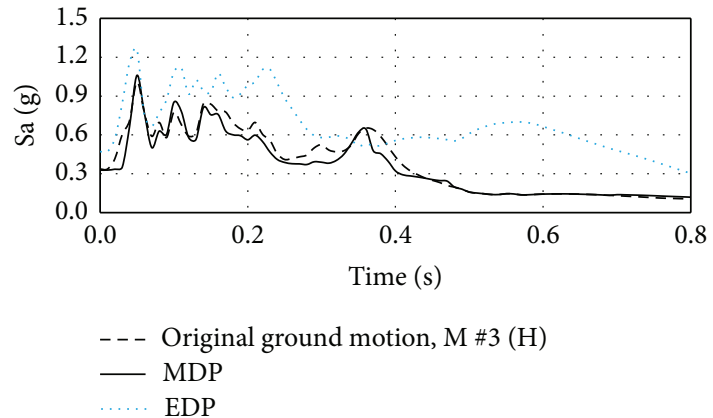

(a)

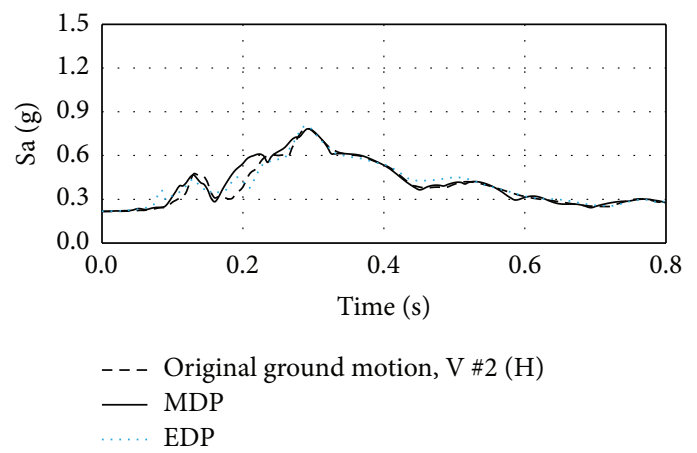

(c)

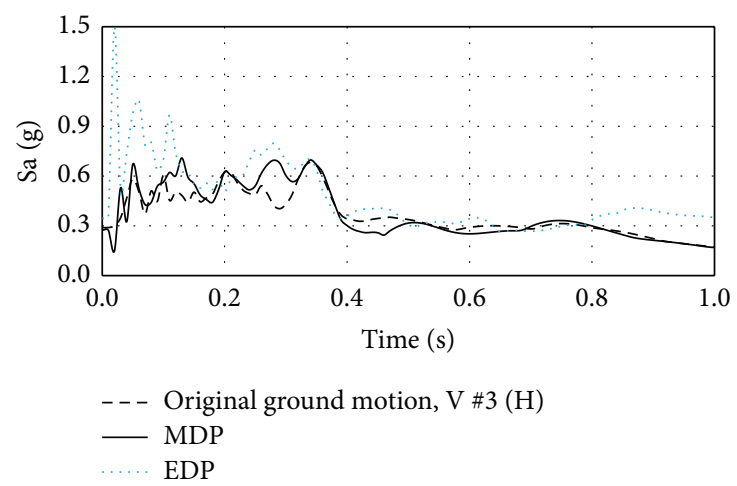

(e)

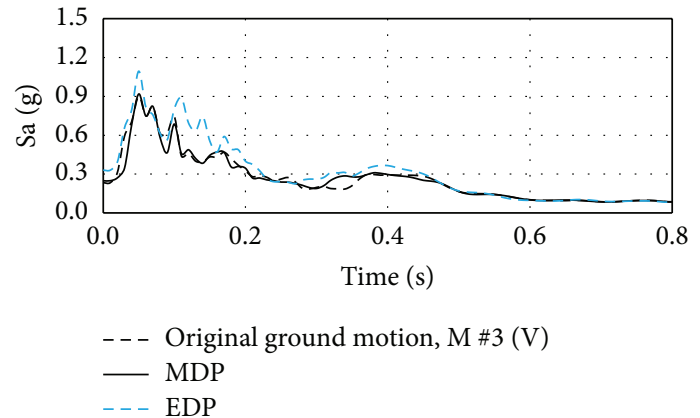

(b)

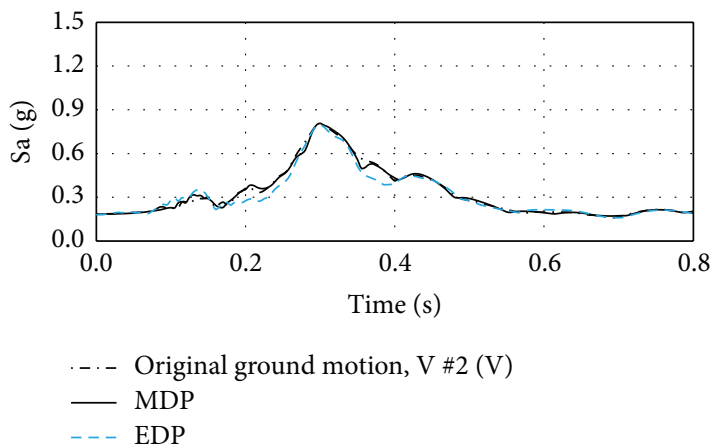

(d)

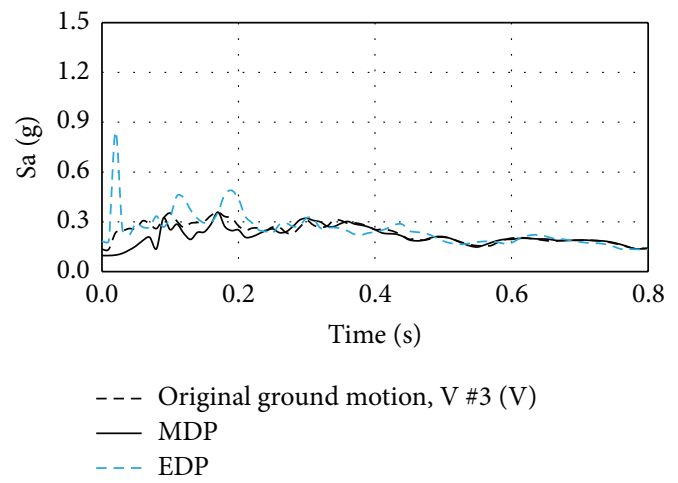

(f)

FIgURE 6: Response spectra of the original and deconvolved ground motions for G-1 in Montreal: (a) M number 3(H); (b) M number 3(V); (c) V number 2(H); (d) V number 2(V); (e) V number 3(H); and (f) V number 3(V).

case of $\mathrm{M}$ number 3 ground motion. The maximum values $R^{2}$ achieved for $\mathrm{M}$ number $3(\mathrm{H})$ by MDP and EDP are 0.984 and 0.898 , respectively (Figure $7(\mathrm{a})$ ), while those for $\mathrm{M}$ number $3(\mathrm{~V})$ are 0.982 and 0.958 , respectively (Figure $7(\mathrm{~b})$ ). It is observed that, for MDP, the value of $R^{2}$ approaches relatively more smoothly and converges well in both cases, while the $R^{2}$ values for EDP fluctuate at different iterations and the convergence is poor. The maximum values of $R^{2}$ achieved for $\mathrm{V}$ number $2(\mathrm{H})$ by MDP and EDP are found to be 0.993 and 0.995 (Figure 7(c)), respectively, while those for $\mathrm{V}$ number $2(\mathrm{~V})$ are 0.999 and 0.997 (Figure $7(\mathrm{~d})$ ), respectively. In the case of $\mathrm{V}$ number 2 ground motion, the results obtained by both MDP and EDP are satisfactory, and the $R^{2}$ values converge very smoothly in both cases. However, in case of
$\mathrm{V}$ number 3 ground motion, the results obtained from EDP are not satisfactory. The maximum values of $R^{2}$ achieved for $\mathrm{V}$ number $3(\mathrm{H})$ by MDP and EDP are 0.958 and 0.887 , respectively (Figure $7(\mathrm{e})$ ), while those for $\mathrm{V}$ number $3(\mathrm{~V})$ are 0.966 and 0.822 , respectively (Figure $7(\mathrm{f})$ ).

From the above results, it can be concluded that the performance of EDP in the cases of low-frequency ground motions is better than that in the cases of high-frequency ground motions. However, in some cases, even for lowfrequency ground motions, such as $\mathrm{V}$ number 3 , the performance of EDP is not acceptable. MDP shows a satisfactory performance for both low- and high-frequency ground motions. Figure 8 presents the response spectra of the deconvolved ground motions for $\mathrm{M}$ number 1 and $\mathrm{V}$ number 


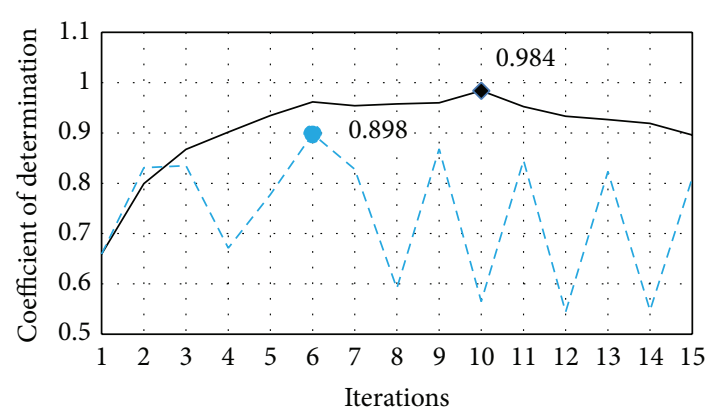

(a)

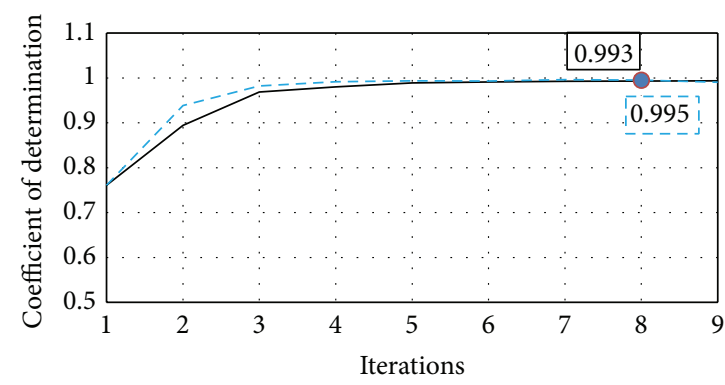

(c)

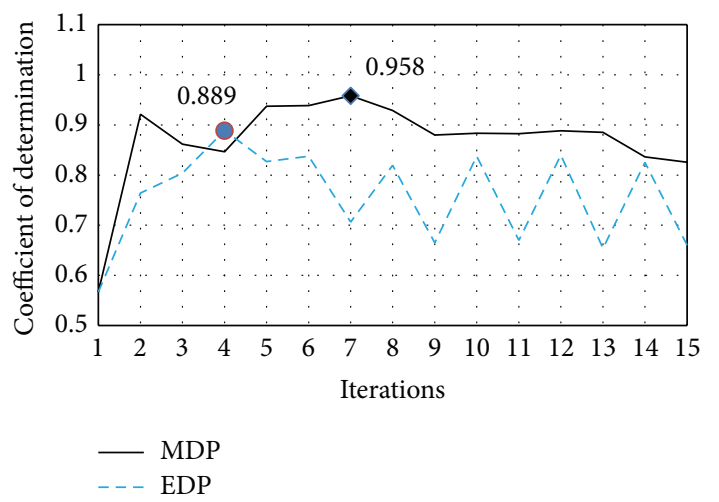

(e)

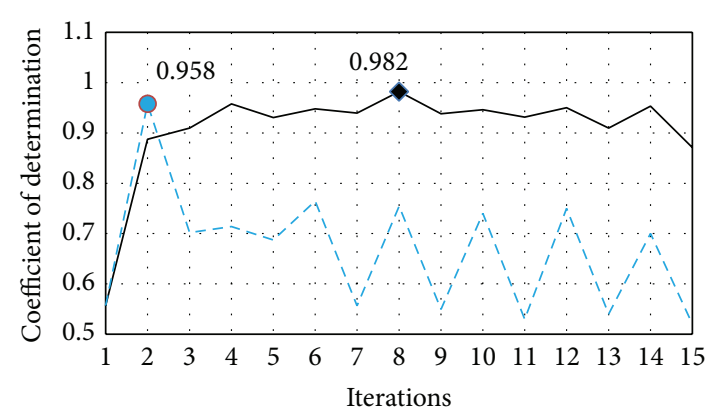

(b)

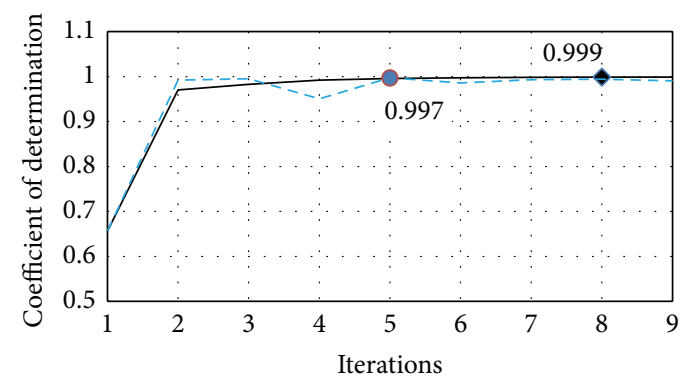

(d)

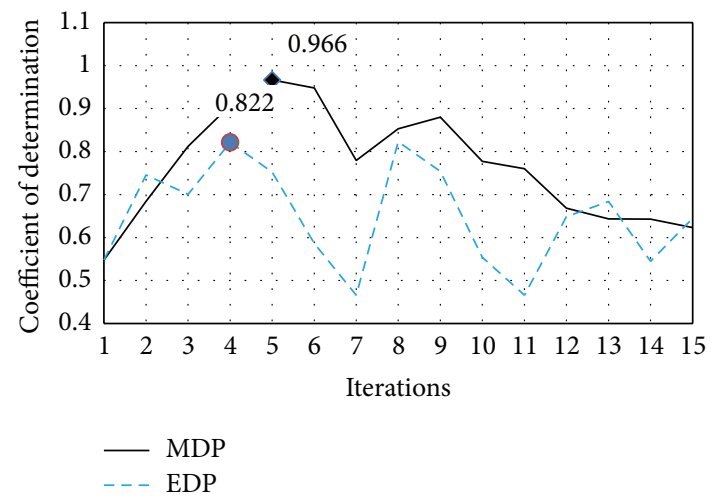

(f)

Figure 7: Coefficient of determination $\left(R^{2}\right)$ for deconvolved ground motions for Geometry G1: (a) M number 3(H); (b) M number 3(V); (c) V number 2(H); (d) V number 2(V); (e) V number 3(H); and (f) V number 3(V).

1 for the dam-foundation system G-2 with MDP and the original ground motions. The results of the deconvolution using EDP have been omitted as they are found to be incorrect in some cases as observed in dam configuration G-1. As the quality of the deconvolution process affects the response of a dam-foundation system, the performance of the deconvolution procedure used in the study is very important. The case study presented in this paper assumes a linear elastic foundation. However, since the deconvolution procedure is iterative, a nonlinear material behavior can be modeled for the foundation.

\section{Conclusions}

The study presents a modified deconvolution procedure for the deconvolution of input ground motions for the use in the seismic response analysis of dam-foundation systems. While the performance of the existing deconvolution procedure is generally good for low-frequency ground motions, it may not work in all such cases; the performance of the procedure is found to be quite poor when a ground motion has high-frequency contents (e.g., for Montreal). The modified deconvolution procedure is found to perform well for both high-frequency and low-frequency ground motions. It is also observed that the deconvolution by EDP requires more iterations and the convergence is poorer compared to MDP. It is important here to note that while only two-dimensional models are considered here, the modified deconvolution procedure proposed in this study is expected to be more effective for three-dimensional damfoundation models. Further study is required in that direction. 


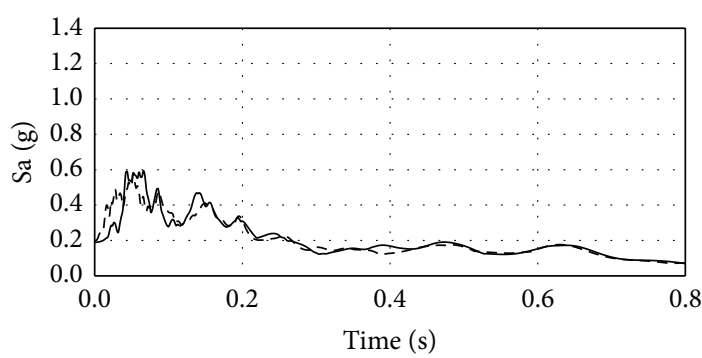

- - - Original ground motion, $\mathrm{M} \# 1(\mathrm{H})$ - MDP

(a)

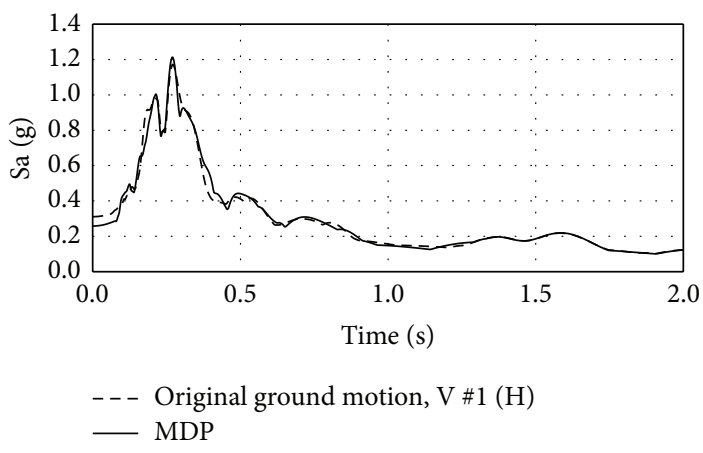

(c)

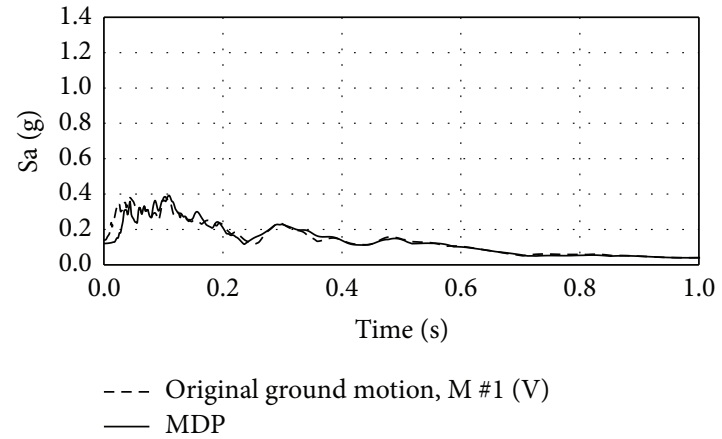

(b)

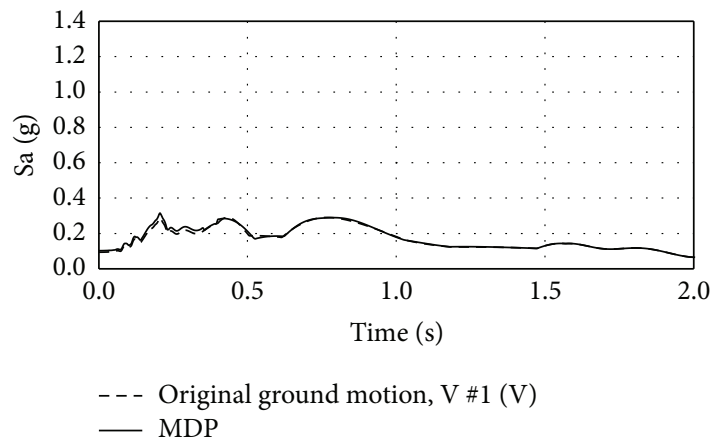

(d)

FIGURE 8: Deconvolved ground motions with MDP for dam-foundation, G2: (a) M number 1(H); (b) M number 1(V); (c) V number 1(H); and (d) V number $1(\mathrm{~V})$.

\section{Conflict of Interests}

The authors declare that there is no conflict of interests regarding the publication of this paper.

\section{Acknowledgment}

The financial assistance provided by the Natural Sciences and Engineering Research Council of Canada is gratefully acknowledged.

\section{References}

[1] Canadian Dam Association, Dam Safety Guidelines, Canadian Dam Association, 2007.

[2] USSD, Observed Performance of Dams During Earthquakes, vol. 2, United States Society on Dams, 2000.

[3] Japan Society of Civil Engineers, The 1999 Chi Chi Earthquake, Taiwan Investigation into the Damage to Civil Engineering Structures, Japan Society of Civil Engineers, Tokyo, Japan, 1999.

[4] B. A. Bolt and W. K. Cloud, "Recorded strong motion on hsinfengkiang dam ,China," Bullentin of the Seismological Society of America, vol. 64, no. 4, pp. 1337-1342, 1974.

[5] J. F. Hall, "The dynamic and earthquake behaviour of concrete dams: review of experimental behaviour and observational evidence," Soil Dynamics and Earthquake Engineering, vol. 7, no. 2, pp. 58-121, 1988.

[6] A. Garabedian, A. Bagchi, A. Joshi et al., " Monitoring dam behaviour using innovative approaches based on linear and nonlinear techniques," in Proceedings of the Annual Conference of the Canadian Dam Association (CDA '06), Quebec City, Canada, 2006.

[7] A. Garabedian, A. Bagchi, A. Joshi, and J. Dong, "Developing an intelligent system for modelling the dam behaviour based on statistical pattern matching of sensory data," in Proceedings of the International Conference on Computing and Decision Making in Civil and Building Engineering, Montreal, Canada, June 2006.

[8] P. Chakrabarti and A. K. Chopra, "Hydrodynamic effects in earthquake response of gravity dams ," Journal of the Structural Division, vol. 100, no. 6, pp. 1211-1224, 1974.

[9] G. Fenves and A. K. Chopra, "Effects of reservoir bottom absorption and dam-water-foundation rock interaction on frequency response functions for concrete gravity dams," Earthquake Engineering \& Structural Dynamics, vol. 13, no. 1, pp. 1331, 1985.

[10] R. Clough, K. Chang, H. Q. Chen, and Y. Ghanaat, Dynamic Interaction Effects in Arch Dams, UCB/EERC-85-11, Earthquake Engineering Reserach Center, Oakland, Calif, USA, 1985.

[11] P. Léger and M. Boughoufalah, "Earthquake input mechanisms for time-domain analysis of dam-foundation systems," Engineering Structures, vol. 11, no. 1, pp. 37-46, 1989.

[12] R. B. Reimer, "Deconvolution of seismic response for linear systems," Tech. Rep. UCB/EERC-73/10, Earthquake Engineering Research Center, University of California, Berkeley, Calif, USA, 1973.

[13] P. B. Schnabel, J. Lysmer, and H. B. Seed, "SHAKE, a computer program for earthquake response analysis of horizontally layered sites," UCB/EERC-72/12, Earthquake Engineering 
Research Center, University of California, Berkeley, Calif, USA, 1972.

[14] V. Luk, B. Spencer, I. Lann, and R. Dameron, Parametric Evaluation of Seismic Behavior of Freestanding Spent Fuel Dry Cask Storage Systems, NUREG /CR-6865,SAND2004-5794P, Sandia National laboratories, Office of Nuclear Regulatory Reserach, U.S. Nuclear Regulatory Commission, Washington, DC, USA, 2005.

[15] I. Polam, H. Law, and C. T. Yang, "Modeling of seismic wave scattering on pile groups and caissons," Tech. Rep. MCEER-070017. MCEER, University at Buffalo, New York, NY, USA, 2007.

[16] Abaqus, Abaqus Theory Manual, Version 6.11, Dassault Systèmes, 2011.

[17] G. S. Sooch and A. Bagchi, "Effect of seismic wave scattering on the response of dam-reservoir-foundation systems," in Proceedings of the 15th World Conference on Earthquake Engineering (WCEE '12), Lisbon, Portugal, 2012.

[18] J. W. Cooley and J. W. Tukey, "An algorithm for the machine calculation of complex Fourier series," Mathematics of Computation, vol. 19, pp. 297-301, 1965.

[19] H. Liang, C. Bailey, and T. Dreese, "Stability evaluation of leftmost power-unit monoliths of the Three Gorges Dam," in Proceedings of the 31st Annual USSD Conference, U.S. Society of Dams, San Diego, Calif, USA, 2011.

[20] R. L. Gupta, O. N. Bajpai, and P. K. Alagh, "Lower Siang H.E. Project-( 9x $300 \mathrm{MW})$, India," International Journal on Hydropower \& Dams, 2009.

[21] A. Bayraktar, T. Türker, M. Akköse, and S. Ateş, “The effect of reservoir length on seismic performance of gravity dams to near-and far-fault ground motions," Natural Hazards, vol. 52, no. 2, pp. 257-275, 2009.

[22] R. Tremblay, M. Eeri, G. M. Atkinson, and M. Eeri, "Comparative study of the inelastic seismic demand of eastern and western Canadian sites," Earthquake Spectra, vol. 17, no. 2, pp. 333-358, 2001.

[23] PEER, Pacific Earthquake Engineering Research Center, NGA Database, 2012, http://peer.berkeley.edu. 


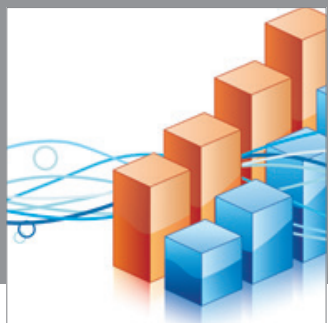

Advances in

Operations Research

mansans

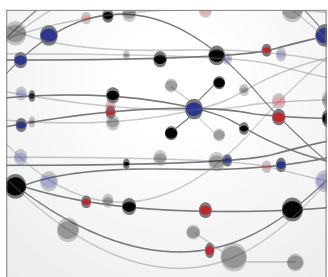

The Scientific World Journal
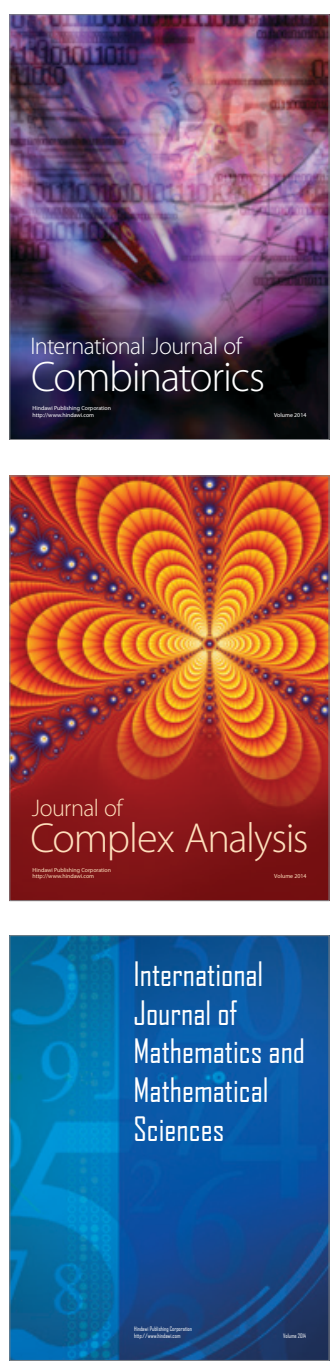
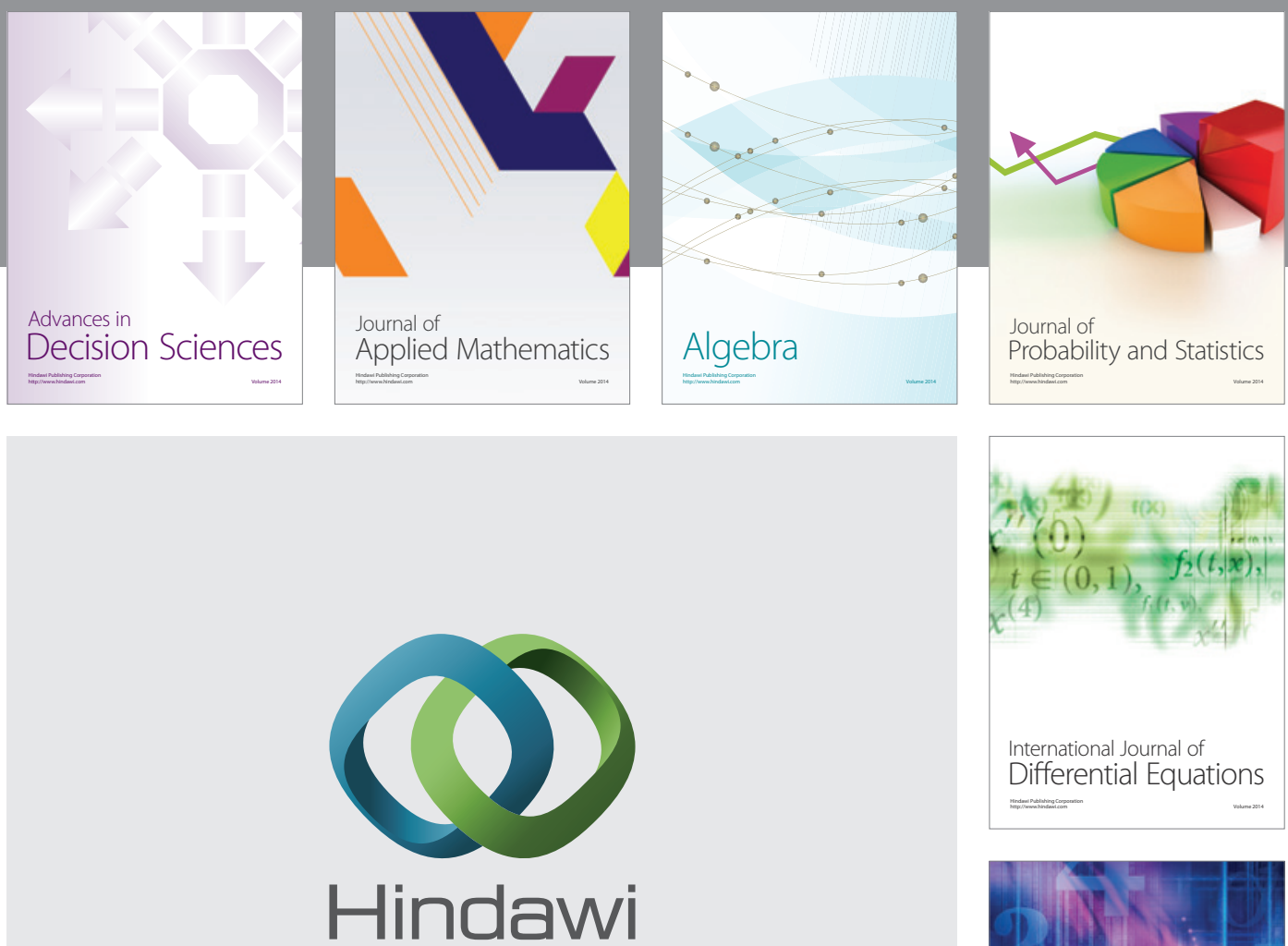

Submit your manuscripts at http://www.hindawi.com
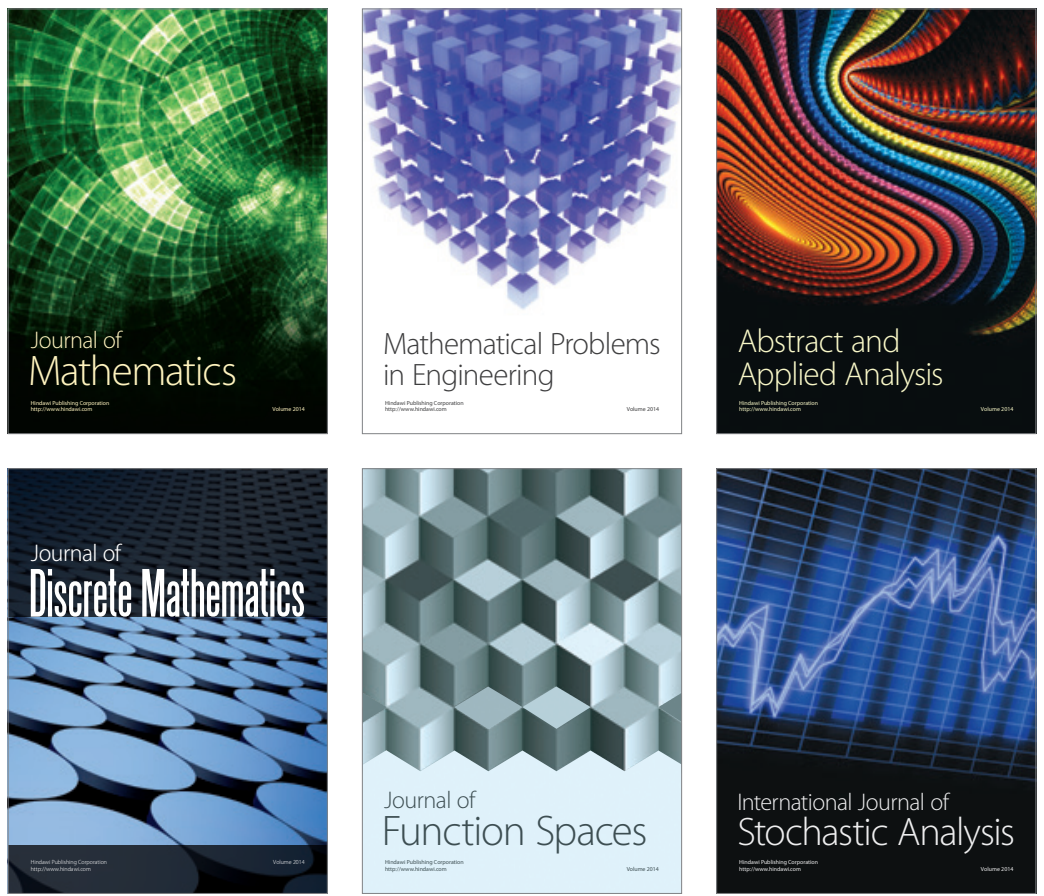

Journal of

Function Spaces

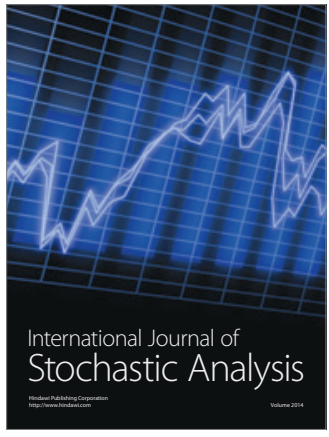

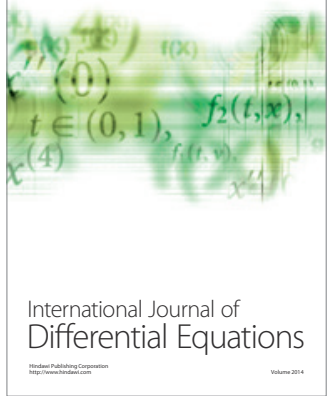
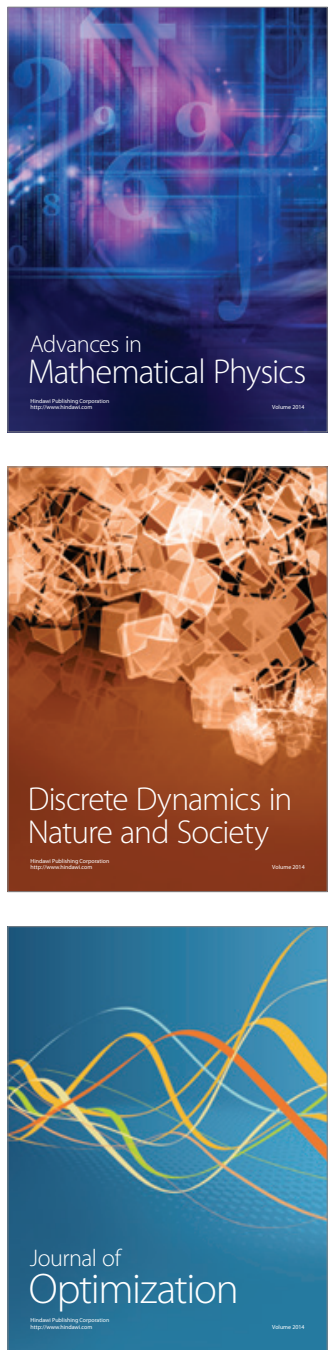